IZIQUE, Valentina Squizato; NUNES, Guilherme de Aquino Ita; SPINIELLI, André Luiz Pereira; RUSSI, Sofia

Covas. Educação e(m) Direitos Humanos: propostas de uma pedagogia crítica pensada a partir de bell hooks e Paulo Freire. Dignidade Re-Vista, v.7, n.12, jul 2021.

\title{
Educação e(m) Direitos Humanos: propostas de uma pedagogia crítica pensada a partir de bell hooks e Paulo Freire*
}

Education and/in Human Rights: proposals for a critical pedagogy thought from bell hooks and Paulo Freire

André Luiz Pereira Spinielli andre.spinieli@unesp.br

Mestrando em Direito (UNESP).

Especialista em Direitos Humanos (FACICA)

\section{Sofia Covas Russi}

sofiacovasrussi@gmail.com

Graduanda em Direito (FDF). Bolsista de

Iniciação Científica (FDF)

\author{
Valentina Squizato Izique \\ valentinaizique@gmail.com \\ Graduanda em Direito (FDF)
}

\section{Guilherme de Aquino Ita Nunes guilhermeita80@gmail.com}

Graduando em Direito (FDF), com período sanduíche na Universidade de Lisboa

(UL), e em Letras (USP)

\section{Resumo}

A reprodução de concepções eurocêntricas de direitos humanos implica a perda do empoderamento de sujeitos sociais vulneráveis. Por meio da afirmação de um diálogo entre as pedagogias críticas de bell hooks e Paulo Freire, este artigo visa identificar a possibilidade da educação em direitos humanos fundada em perspectivas transformadoras da realidade dos sujeitos participantes do processo de ensino-aprendizagem.

Palavras-chave: Vulnerabilidades sócio-históricas; educação crítica; autonomia do sujeito.

\begin{abstract}
The reproduction of Eurocentric conceptions of human rights implies the loss of the empowerment of vulnerable social subjects. Through the affirmation of a dialogue between the critical pedagogies of bell hooks and Paulo Freire, this article aims to identify the possibility of an education in human rights based on perspectives that transform the reality of the participants in the teaching-learning process.
\end{abstract}

Keywords: Socio-historic vulnerabilities; critical education; subject autonomy.

\footnotetext{
* Este texto aborda, de forma organizada, as reflexões desenvolvidas sobre educação crítica em direitos humanos e pedagogias alternativas para o ensino do direito (e dos direitos humanos) no âmbito do Núcleo de Estudos Latino-Americanos em Direitos Humanos (NELADH). Em especial, agradecemos aos demais membros do grupo, que, embora não tenham participado diretamente da construção deste trabalho, foram fundamentais para assentar uma tese central sobre o tema discutido.
} 
IZIQUE, Valentina Squizato; NUNES, Guilherme de Aquino Ita; SPINIELLI, André Luiz Pereira; RUSSI, Sofia

Covas. Educação e(m) Direitos Humanos: propostas de uma pedagogia crítica pensada a partir de bell hooks e Paulo Freire. Dignidade Re-Vista, v.7, n.12, jul 2021.

\section{Introdução}

Em cenários regidos pelo colonialismo cultural e pelo fascismo social (Rubio, 2009, p.368), a pedagogia dos direitos humanos é reproduzida de acordo com uma mentalidade moldada e imposta por grupos hegemônicos em face de sujeitos considerados vulneráveis, o que implica a concretização de posições conformistas e passivas sobre a difusão do conhecimento e da prática sobre essas garantias (Rubio, 2009, p.367). Nesses contextos, a compreensão jurídico-social acerca dos direitos humanos está vinculada a concepções restritivas e pautadas tanto no simplismo quanto em uma ignorância social seletiva, que permite aplicar direitos humanos em determinados casos e desaprová-los em outros (Rubio, 2009, p.367).

Reclamar uma educação crítica em direitos humanos é indispensável. A reprodução de compreensões eurocêntricas, acríticas e não populares acerca desses direitos humanos legitima diariamente uma epistemologia calcada na separação entre aquilo que se afirma no campo formal e o que é de fato materializado na realidade cotidiana, cuja base é "(...) a passividade na hora de construir e ensinar dia após dia e em todos os lugares sociais os direitos humanos"1 (Rubio, 2009, p.368, a tradução é nossa). Assim, a concepção de educação em direitos humanos que tem por enfoque valores dissociados de perspectivas sócio-históricas, ou exclusivamente abordagens que reafirmam conceitos básicos no tema, é insuficiente (Rubio, 2009, p.377-8).

Em realidade, trazer à tona os caracteres políticos intrínsecos aos diferentes espaços sociais que inspiram e respiram a educação em direitos humanos implica (re)pensar a disputa entre experiências hegemônicas e contra-hegemônicas na construção de uma pedagogia crítica sobre essas garantias, que diferencie "a educação como prática da liberdade e a educação que só trabalha para reforçar a dominação" (hooks, 2013, p.12). Ensinar e lutar pelos direitos humanos em contextos nos quais preponderam os altos índices de desigualdade social, violência e subtração da cidadania constitui uma prática da liberdade (hooks, 2013, p.12) ou a construção de uma pedagogia da autonomia dos sujeitos que são partes do processo de ensinoaprendizagem (Freire, 2014, p.65).

A partir desse panorama, o objetivo deste trabalho é apresentar a construção de uma vertente crítica da educação em direitos humanos por meio do diálogo teórico entre as

\footnotetext{
1 “[...] la pasividad a la hora de construir y enseñar día a día y en todos los lugares sociales, derechos humanos" (Rubio, 2009, p.368).

DIGNIDADE RE-VISTA | ISSN2525-698X| 2021 | V. VII | N. 12 | Educação Prática Libertadora - heranças dos 100 anos de Paulo Freire e Dom Paulo Arns. Pastoral Universitária Anchieta PUC-RIO.
} 
IZIQUE, Valentina Squizato; NUNES, Guilherme de Aquino Ita; SPINIELLI, André Luiz Pereira; RUSSI, Sofia

Covas. Educação e(m) Direitos Humanos: propostas de uma pedagogia crítica pensada a partir de bell hooks e Paulo Freire. Dignidade Re-Vista, v.7, n.12, jul 2021.

pedagogias de bell hooks ${ }^{2}$ e Paulo Freire. Metodologicamente, o artigo se fundamenta na pesquisa descritiva documental, cujo desenvolvimento é realizado de acordo com a abordagem literária sobre pedagogia crítica e educação em direitos humanos. Para a concretização dos objetivos traçados, o artigo se divide em três capítulos. No primeiro, são abordados os principais fatores que nos permitem afirmar a existência de uma crise educacional em direitos humanos. No segundo, apresenta-se o diálogo entre as pedagogias críticas em bell hooks e Paulo Freire em uma vertente aplicada aos direitos humanos. No terceiro, recorre-se à ideia da pedagogia crítica como alternativa à superação da crise hegemônica da educação em direitos humanos.

\section{Hegemonia e acriticidade: afirmação da crise educacional em direitos humanos}

A construção da dimensão crítica do direito (e dos direitos humanos) reclama necessariamente uma formação cidadã pensada tanto para o empoderamento de atores sociais competentes quanto para a transformação da própria realidade material que os circunda. No entanto, especialmente em espaços socioeconomicamente periféricos, a educação em e para os direitos humanos tem sido alvo de concepções estreitas, reduzidas e vinculadas a aspectos eurocêntricos (Rubio, 2009, p.366), cujos efeitos se instalam na afirmação do abismo existente entre o teórico e o prático. A constatação de um viés acrítico em relação à educação em direitos humanos na contemporaneidade tem como fundamento a assimilação do mito da neutralidade do direito, que sugere ser a interpretação e a aplicação dogmática dessas garantias suficientes e distanciadas dos conflitos sociais (Machado, 2009, p.52).

O despontar de uma cultura de direitos humanos extremamente conformada com os níveis de desigualdade social e a (in)aplicabilidade dessas garantias na realidade objetiva tem como princípio o esgotamento dos paradigmas jurídicos e de seu potencial transformador (Rubio, 2009, p.267; Machado, 2009, p.109). De fato, o liberalismo como ideologia jurídica e o dogmatismo apregoado como modelo epistemológico do direito deixaram de ser bases seguras para fornecer respostas e soluções adequadas aos problemas sociais (Machado, 2009, p.109), o que repercute diretamente no sentido prático que a educação em direitos humanos requer. $\mathrm{O}$

\footnotetext{
2 Pseudônimo utilizado por Gloria Jean Watkins em homenagem à sua bisavó materna. A autora enfatiza a necessidade de se utilizar seu nome em letras minúsculas, o que se deve à sua proposta de enfocar suas ideias, e não sua pessoa. Por se tratar de um referencial teórico fundamental do trabalho e em respeito à própria voz da autora, neste trabalho empregaremos todos as citações em letras minúsculas.
}

DIGNIDADE RE-VISTA | ISSN2525-698X| 2021 | V. VII | N. 12 | Educação Prática Libertadora - heranças dos 100 anos de Paulo Freire e Dom Paulo Arns. Pastoral Universitária Anchieta PUC-RIO. 
IZIQUE, Valentina Squizato; NUNES, Guilherme de Aquino Ita; SPINIELLI, André Luiz Pereira; RUSSI, Sofia

Covas. Educação e(m) Direitos Humanos: propostas de uma pedagogia crítica pensada a partir de bell hooks e Paulo Freire. Dignidade Re-Vista, v.7, n.12, jul 2021.

que se visualiza nesse campo é justamente a afirmação de um modelo de educação em direitos humanos notadamente funcional, influenciado por aquilo que o mercado jurídico demanda e por percepções acríticas e vinculadas aos interesses hegemônicos (Machado, 2009, p.109, 128).

$\mathrm{Na}$ verdade, o propósito da educação voltada aos direitos humanos é fazer com que os sujeitos envolvidos no processo de ensino-aprendizagem se engajem socialmente a fim de “compreender não só as diversas formas de opressão e dominação, mas também desvelar mistificações ideológicas nas relações sociais" (Carvalho; Estêvão, 2013, p.408). Romper com a proposta acrítica da educação em direitos humanos significa fornecer aos atores sociais subsídios teóricos e práticos úteis a uma formação que tenha dimensões críticas e que externem um pensamento sobre direitos cada vez mais emancipador e menos exploratório. Em outros termos, a educação em direitos humanos crítica representa a contrariedade à concepção individualista dos direitos e à reprodução tecnicista do saber, que "se realiza pela monótona repetição dos códigos sem qualquer abordagem das dimensões substantivas, ou históricas, do direito" (Machado, 2009, p.128).

Como mecanismo formativo para o exercício da cidadania, que encontra limites na acriticidade e na naturalização social de concepções dominantes, pode-se dizer que a educação crítica em direitos humanos possui ao menos quatro funções contra-hegemônicas. Essas funções estão diretamente relacionadas ao papel transformador que a criticidade jurídica exerce na realidade objetiva, permitindo que se enxergue os direitos humanos como fenômenos ideológicos (Machado, 2009, p.35) e cuja formatação é fruto de operações que expressam os interesses de indivíduos e grupos sociais.

A primeira função está vinculada à construção de subsídios que contribuam diretamente para a formação do sujeito enquanto cidadão consciente de sua posição social e de seus direitos e deveres (Magendzo, 2006, p.23). A segunda diz respeito à tendência de educar para a busca efetiva de concretização dos direitos humanos, permitindo a reformulação do paradigma contemporâneo. A terceira função se relaciona com o processo de formatação da criticidade e do empoderamento de atores sociais para a realização de mudanças profundas na realidade objetiva, fazendo com que leis e tribunais sejam "instrumentos de mudança social e não apenas de manutenção do status quo" (Machado, 2009, p.15). A quarta se vincula à capacidade de desnudar desigualdades existentes no lugar social de cada sujeito envolvido no processo de ensino-aprendizagem, de modo que lhes permita desenvolver sensibilidades frente às 
IZIQUE, Valentina Squizato; NUNES, Guilherme de Aquino Ita; SPINIELLI, André Luiz Pereira; RUSSI, Sofia Covas. Educação e(m) Direitos Humanos: propostas de uma pedagogia crítica pensada a partir de bell hooks e Paulo Freire. Dignidade Re-Vista, v.7, n.12, jul 2021.

necessidades de outras pessoas e tratá-las como iguais "a partir de horizontalidades, ampliando o âmbito de garantias de direitos a lugares cotidianos e não só judiciais” (Rubio, 2017, p.21).

Em meio à crise educacional dos direitos humanos na contemporaneidade, propor alternativas a esse problema e mecanismos que permitam (re)pensar a educação em direitos humanos representa um fator contrário à hegemonia e ao senso acrítico de que esse fenômeno foi informado. Em realidade, trata-se de localizar opções que permitam a reformulação cultural dos atores sociais a partir de uma perspectiva que redefina a existência do abismo entre o teórico e o prático e, mais que isso, permita a construção intercultural da cidadania e a promoção libertadora dos direitos humanos, possibilitando o reconhecimento de outras pessoas como sujeitos de direitos e que grupos que sobrevivem à margem da sociedade tenham voz e vez. A partir de um paradigma crítico racial, bell hooks detalha seus caminhos até a universidade, indicando a educação acrítica como instrumento de fomento à desigualdade:

\begin{abstract}
Quando entramos em escolas brancas, racistas e dessegregadas, deixamos para trás um mundo onde os professores acreditavam que precisavam de um compromisso político para educar corretamente as crianças negras. De repente, passamos a ter aula com professores brancos cujas lições reforçavam os estereótipos racistas. Para as crianças negras, a educação já não tinha a ver com a prática da liberdade. (...) A escola ainda era um ambiente político, pois éramos obrigados a enfrentar a todo momento os pressupostos racistas dos brancos, de que éramos geneticamente inferiores, menos capacitados que os colegas, até incapazes de aprender. Apesar disso, essa política já não era contra-hegemônica. O tempo todo, estávamos somente respondendo e reagindo aos brancos. (2013, p.12)
\end{abstract}

\title{
Pedagogia crítica como alternativa à crise educacional dos direitos humanos
}

A escola moderna foi socialmente construída sobre paradigmas de segregação, que permitiram a separação entre sujeitos a partir de critérios etários, raciais, socioeconômicos e de gênero, e operaram a materialização de "diferenças, distinções e desigualdades, registrando na prática escolar e nas relações sociais os modos, as maneiras de agir e pensar, onde atuar" (Reis; Brabo, 2012, p.166). Diante da assimilação do estado de crítica ausente, a infiltração do pensamento crítico no campo da pedagogia dos direitos humanos possibilitou a problematização de temas que se inserem na realidade social de cada sujeito pertencente à relação de ensino-aprendizagem, de modo que essa dimensão tem por finalidade levar para além dos muros das escolas o saber praticável sobre direitos, além de permitir enxergar no outro sua condição humana e suas necessidades. 
IZIQUE, Valentina Squizato; NUNES, Guilherme de Aquino Ita; SPINIELLI, André Luiz Pereira; RUSSI, Sofia

Covas. Educação e(m) Direitos Humanos: propostas de uma pedagogia crítica pensada a partir de bell hooks e Paulo Freire. Dignidade Re-Vista, v.7, n.12, jul 2021.

Forjada sob o modelo de uma educação libertadora ou de uma pedagogia engajada, a proposta central da introdução da criticidade no campo da educação em direitos humanos é fornecer instrumentos que sejam suficientes aos atores sociais para problematizar e pensar criticamente a realidade, na medida em que interagem com o mundo ao seu redor (Freire, 1987, p.39). A ideia fundamental da pedagogia crítica em direitos humanos está na superação do modelo tradicional de educação, a partir do qual determinados sujeitos sociais legitimados transferem conhecimentos e valores aos educandos em troca da assimilação de meros conceitos e compreensões estáveis, transformando o aluno em mero espectador (Freire, 1987, p.39). Logo, a pedagogia crítica coloca "a exigência da superação da contradição educador-educandos" (Freire, 1987, p.39).

Para além dessa dimensão, a pedagogia crítica em direitos humanos possui o condão de fazer da opressão e de seus desdobramentos objeto necessário para a reflexão e a ação transformadora, a práxis, de grupos situados à margem da sociedade (Padilha, 2008, p.25), cujo resultado é a luta pela libertação social desses sujeitos (Freire, 1987, p.32). Nesse sentido, a educação crítica em direitos humanos demanda a interação entre os atores sociais inseridos no processo de ensino-aprendizagem teórico e prático dessas garantias, de modo que haja a presença de subjetividades distintas que lidam diretamente com direitos humanos, como o educador, o educando, vítimas de violações estruturais, defensores e promotores de direitos (Carbonari, 2010, p.62). Logo, pode-se dizer que a função da educação crítica em direitos humanos não é a mera reprodução de conceitos estabilizados, mas sim a constituição de indivíduos capazes de transformar as realidades nas quais estão inseridos por meio da autonomia e da emancipação (Rodrigues; Silva, 2019, p.162).

Trabalhar a pedagogia crítica como alternativa à crise contemporânea da educação em direitos humanos, que se conforma por meio de aspectos eurocêntricos, acríticos e plasmados na separação entre o teórico e o prático, significa levar a sério a legitimidade do "sonho éticopolítico da superação da realidade injusta" (Freire, 2000, p.43). O paradigma da educação em direitos humanos, que se apresenta de modo crítico e alinhada à realidade histórico-social de sujeitos postos à margem, representa um convite para a luta contra as diferentes formas de violações e violências contra os direitos humanos (Padilha, 2008, p.28), que vão desde a ausência estrutural de sensibilidade frente às diferenças até a falta de esperança depositada em ideologias jurídicas que deixam de levar em consideração a realidade material como fonte para o desenvolvimento do direito, contentando-se com elementos formalizados em lei. 
IZIQUE, Valentina Squizato; NUNES, Guilherme de Aquino Ita; SPINIELLI, André Luiz Pereira; RUSSI, Sofia

Covas. Educação e(m) Direitos Humanos: propostas de uma pedagogia crítica pensada a partir de bell hooks e Paulo Freire. Dignidade Re-Vista, v.7, n.12, jul 2021.

A educação em direitos humanos não se limita ao formal ou institucional, uma vez que também deve abarcar elementos sociais, epistemológicos, políticos, culturais e econômicos (Walsh, 2017, p.38). Como alternativa à crise apresentada, a prática da educação em direitos humanos deve ter o potencial de elevar as classes sociais subalternas à assimilação de valores básicos sobre direitos humanos, estabelecendo compromisso e responsabilidade de combate às práticas violatórias dessas garantias (Tibbitts, 2002, p.164), o que, como consequência, permitirá uma transformação social orientada para o reconhecimento de indivíduos e grupos vulneráveis como sujeitos de direitos humanos. Por inexistir prática social mais política que o exercício da educação, suas potencialidades estão voltadas à ruptura de estados de dominação e alienação social, permitindo denunciar tais situações e se converter em uma ferramenta de emancipação e luta contra perspectivas hegemônicas de direitos humanos (Walsh, 2017, p.3839).

Para servir como epistemologia alternativa à crise da educação em direitos humanos e ir de encontro às concepções hegemônicas acerca desses direitos, a pedagogia crítica deve adotar como finalidade a conscientização individual e coletiva (Walsh, 2017, p.38-39). Como estândares de uma proposta pedagógica crítica para os direitos humanos, bell hooks e Paulo Freire possuem aspectos similares em suas reflexões, indicando que uma educação "que nos ensina a lutar pelos nossos direitos e a tornar o processo educativo mais plenamente humano" (Padilha, 2008, p.28) representa conceber direitos humanos como possibilidade crítica e transformadora da realidade. Trata-se de entender a educação em direitos humanos como a necessidade de mobilização crítica e direcionada à reinvenção da realidade (Freire, 2001, p.99).

\section{Desenhos da pedagogia crítica para os direitos humanos em bell hooks e Paulo Freire}

Os pensamentos de bell hooks e Paulo Freire são elementos-chave para a formatação de uma leitura crítica da educação em direitos humanos e de sua insuficiência transformadora. De fato, a simbiose entre as reflexões pedagógicas de ambos se revela na tentativa de eleger mecanismos transgressivos que tenham como finalidade única a consolidação de uma educação libertadora, pensada a partir de razões histórico-sociais, responsáveis por modelar o sentido existencial de grupos situados no campo da marginalidade social. Em outros termos, significa dizer que os caminhos da pedagogia crítica hookiana e freiriana para os direitos humanos consistem no estabelecimento de um diálogo amplo e firmado para além da sala de aula 
IZIQUE, Valentina Squizato; NUNES, Guilherme de Aquino Ita; SPINIELLI, André Luiz Pereira; RUSSI, Sofia Covas. Educação e(m) Direitos Humanos: propostas de uma pedagogia crítica pensada a partir de bell hooks e Paulo Freire. Dignidade Re-Vista, v.7, n.12, jul 2021. institucionalizada, afastando-se da sistemática bancária da educação ${ }^{3}$ (Freire, 1987, p.34) para constituir um formato que encontre "formas de ensinar e compartilhar conhecimento de maneira a não reforçar as estruturas de dominação existentes” (hooks, 2017, p.203).

A partir de um viés que associa a teoria crítica racial às pedagogias anticolonialistas e da libertação (hooks, 2017, p.20), bell hooks desenvolve uma proposta teórico-metodológica pautada na perspectiva freiriana que visa ensinar o sujeito social a transgredir, permitindo que a educação seja enfrentada não mais como prática hermética e desprovida de sentido transformador, mas sim como prática da liberdade (hooks, 2017, p.12-3). Educar para a liberdade representa desafiar o modelo tradicional de se pensar e conceber processos pedagógicos e visualizar na sala de aula um campo propício para o ativismo político-social ou um espaço de possibilidades para enxergar as condicionantes histórico-sociais criticamente (hooks, 2017, p.272-3). Por meio da pedagogia engajada, hooks concebe a educação como ato contra-hegemônico que (re)inventa o ser por meio das ideias (hooks, 2017, p.10). Assim, a educação como prática da liberdade é um processo que cria condições necessárias para o aprendizado profundo e vinculado à realidade (hooks, 2017, p.25).

O delineamento da ideia de ensinar a transgredir é desenvolvido no pensamento de hooks a partir do emprego da metodologia de storytelling, pela qual a autora recupera elementos fundamentais de sua trajetória como professora universitária e estabelece um diálogo entre suas experiências e a proposta teórica da pedagogia engajada, identificando as principais dificuldades de sua função social. Ao optar pelo emprego desse método, como mulher negra, hooks busca demonstrar que sujeitos pertencentes a grupos minoritários compreendem os mecanismos sociais de dominação de forma diferenciada dos grupos hegemônicos (Moreira, 2017, p.396). A eleição da narrativa de sua vivência como professora universitária e a confrontação dessas experiências com o panorama teórico da pedagogia crítica têm por finalidade desnudar as discriminações e dificuldades educacionais para os direitos humanos como aspectos concretos da interação cotidiana ${ }^{4}$ (Delgado; Stefanfic, 2001, p.37).

\footnotetext{
${ }^{3}$ Sobre a concepção de educação como sistema bancário, Paulo Freire (1987, p.34) afirma: "Não é de estranhar, pois, que nesta visão 'bancária' da educação, os homens sejam vistos como seres da adaptação, do ajustamento. Quanto mais se exercitem os educandos nos arquivamentos dos depósitos que Ihes são feitos, tanto menos desenvolverão em si a consciência crítica de que resultaria a sua inserção no mundo, como transformadores dele. Como sujeitos".

${ }^{4} \mathrm{~A}$ realidade da autora como mulher negra pertencente à classe trabalhadora foi conformada por três possibilidades existenciais: o casamento, o trabalho como doméstica ou tornar-se professora em escolas periféricas (hooks, 2017, p.10). Tendo presenciado a luta por direitos civis nos Estados Unidos, enquanto aluna de escola na qual parcela majoritária dos professores era composta por negros, hooks compreendeu desde cedo que, para as minorias raciais, "o lecionar - o educar - era fundamentalmente
} 
IZIQUE, Valentina Squizato; NUNES, Guilherme de Aquino Ita; SPINIELLI, André Luiz Pereira; RUSSI, Sofia Covas. Educação e(m) Direitos Humanos: propostas de uma pedagogia crítica pensada a partir de bell hooks e Paulo Freire. Dignidade Re-Vista, v.7, n.12, jul 2021.

A perspectiva hookiana materializa a sala de aula como espaço de resistência e oportunidade para trabalhar pela liberdade e transgressão (hooks, 2017, p.273). Ao transplantarmos esse viés para o campo da educação em direitos humanos, abrem-se duas possibilidades interpretativas para uma pedagogia jurídico-social crítica: a primeira diz respeito ao fato de que, se a pedagogia engajada enfatiza o bem-estar (hooks, 2017, p.28), sua base está na preocupação com o outro, o que implica não apenas um sentido de sensibilização social diante das diferenças e desigualdades, mas também um compromisso ativo dos educadores e educandos em direitos humanos para a mudança social profunda e efetiva; a segunda aponta que os sujeitos envolvidos no processo de ensino-aprendizagem são detentores de conhecimentos que advêm da experiência social, permitindo que, ao serem apresentados em sala de aula, coexistirão com outros modos de saber e, assim, menor será a possibilidade de utilizar a vivência como forma de silenciar o outro (hooks, 2017, p.114).

Como ferramenta hermenêutica útil a uma proposta crítica de educação em direitos humanos, a valorização das experiências de diferentes sujeitos inseridos nesse processo, por permitir a tradução de suas condições e situações sociais e representar ato contrário à hierarquização das diferenças, é fundamental para a produção do conhecimento, da igualdade e de uma educação democrática. Assim como bell hooks, Paulo Freire também assenta importantes estândares para a educação crítica em direitos humanos, uma vez que busca desmistificar a concepção que insere o educador como sujeito e o educando como objeto ${ }^{5}$ (Freire, 2014, p.37). Embora não tenha escrito diretamente sobre direitos humanos, a relação do autor com essa categoria de garantias é expressa a partir da própria pedagogia engajada, uma vez que "os princípios fundadores dos direitos humanos (...) orientam a compreensão do ato educativo freiriano a ponto de o princípio da libertação ser considerado como razão mesmo da educação" (Viola, 2008, p.148).

Ao propor a pedagogia da autonomia como modo de construir a ideia segundo a qual “quem ensina aprende ao ensinar e quem aprende ensina ao aprender" (Freire, 2014, p.37), Paulo Freire busca afirmar tanto o papel do educador na construção cidadã de sujeitos engajados na transformação social quanto da própria educação crítica como mecanismo necessário para a

político, pois tinha raízes na luta antirracista" (hooks, 2017, p.10). Sua formação foi atravessada por professores que possuíam o interesse em transformar os alunos em pessoas devotadas ao estudo e à vida intelectual, o que serviria de mecanismo contra-hegemônico para resistir às estratégias brancas de colonização racista (hooks, 2017, p.10).

${ }^{5}$ Ou que o "formador é o sujeito em relação a quem me considero o objeto, que ele é o sujeito que me forma e eu, o objeto por ele formado" (Freire, 2014, p.37). 
IZIQUE, Valentina Squizato; NUNES, Guilherme de Aquino Ita; SPINIELLI, André Luiz Pereira; RUSSI, Sofia

Covas. Educação e(m) Direitos Humanos: propostas de uma pedagogia crítica pensada a partir de bell hooks e Paulo Freire. Dignidade Re-Vista, v.7, n.12, jul 2021.

resolução de problemas que rodeiam a realidade material dessas pessoas. Uma vez que os atores sociais protagonistas de direitos humanos são seres de cultura, torna-se indispensável a capacidade de assumir a "dependência radical derivada de nossa finitude, estando assim livre para deixar cair as barreiras que não permitem que os outros sejam outros e não um espelho de nós mesmos" (Machado, 2008, p.97) e nos tornarmos autônomos. No campo dos direitos humanos, a perspectiva freiriana da autonomia é hermeneuticamente útil para afirmar a libertação do homem "das cadeias do determinismo neoliberal, reconhecendo que a história é um tempo de possibilidades" (Machado, 2008, p.97).

Desse modo, a conjugação das pedagogias críticas construídas por bell hooks e Paulo Freire como forma de superação da crise paradigmática da educação em direitos humanos perpassa o reconhecimento de que a participação cidadã nesse processo é fundamental não apenas para adquirir consciência formal de direitos, mas também para compreendê-los como parte do desenvolvimento das potencialidades humanas (Viola, 2008, p.149). Seja como pedagogia engajada, seja como pedagogia da autonomia, vincular a educação em direitos humanos à proposta de conscientização crítica pensada por essas teses significa trazer à tona uma nova maneira de se olhar os mecanismos de educação em direitos, que deixam de ser acríticos e hegemônicos para encampar uma dimensão da educação como elemento da “afirmação histórica dos direitos humanos quando o ato pedagógico se constitui como um exercício do diálogo entre educadores e educandos mediados pelo conhecimento (...) e de produzir uma sociedade essencialmente voltada para a prática da democracia" (Viola, 2008, p.149).

\section{Considerações finais}

Este trabalho teve como finalidade explorar a possibilidade de uma educação em direitos humanos fundada em perspectivas transformadoras da realidade dos sujeitos que compõem o processo de ensino-aprendizagem a partir da conjugação das visões pedagógicas de bell hooks e Paulo Freire. Em espaços periféricos, dominados por questões de fascismo social e colonialidade, a educação em direitos humanos tem sido visualizada como insuficiente ou demasiadamente estreita para possibilitar eficazmente um sentido de mudança da realidade material. Esse estado se deve principalmente a dois fatores: a construção de uma cultura de direitos humanos sob o ponto de vista de grupos hegemônicos, que não possuem vivência direta com as desigualdades sociais, violações de direitos e violências; e a dotação de um sentido 
IZIQUE, Valentina Squizato; NUNES, Guilherme de Aquino Ita; SPINIELLI, André Luiz Pereira; RUSSI, Sofia

Covas. Educação e(m) Direitos Humanos: propostas de uma pedagogia crítica pensada a partir de bell hooks e Paulo Freire. Dignidade Re-Vista, v.7, n.12, jul 2021.

acrítico da educação em direitos humanos, que se conforma com a mera reprodução de conceitos básicos, sem contextualizá-los histórico-socialmente na dimensão prática dos educadores e educandos.

A pedagogia crítica representa um significativo instrumento hermenêutico para a educação em direitos humanos. Na verdade, mais que isso, trata-se de mecanismo responsável por fazer com que o homem seja capaz de "assumir com plenitude a sua condição de cidadão, de assumir compromissos e ser por eles responsável" (Viola, 2008, p.149). Em outros termos, pensada a partir dos referenciais teóricos em questão, a educação crítica em direitos humanos sugere a participação cidadã como elemento útil à afirmação da autonomia e da possibilidade de (re)invenção dos direitos humanos por meio de ideias. Conclui-se que, ao se materializar os espaços educacionais como campos de resistência frente às concepções limitadas de direitos humanos pensadas a partir da hegemonia, as pedagogias críticas hookiana e freiriana assumem uma posição de destaque no desenvolvimento dessas garantias e na construção de atores sociais competentes e preocupados em romper com o abismo entre o que se teoriza ou formaliza em direitos humanos e o que é de fato concretizado. 
IZIQUE, Valentina Squizato; NUNES, Guilherme de Aquino Ita; SPINIELLI, André Luiz Pereira; RUSSI, Sofia Covas. Educação e(m) Direitos Humanos: propostas de uma pedagogia crítica pensada a partir de bell hooks e Paulo Freire. Dignidade Re-Vista, v.7, n.12, jul 2021.

\section{Referências bibliográficas}

CARBONARI, Paulo César. Direitos humanos: sugestões pedagógicas. Passo Fundo: Instituto Superior de Filosofia Berthier, 2010.

CARVALHO, Maria Elizete Guimarães; ESTÊVÃO, Carlos Alberto Vilar. Pedagogia crítica e direitos humanos: fundamentos para uma proposta pedagógico-crítica em direitos humanos. Ensaio - Avaliação e Políticas Públicas em Educação, v.21, n.8, p.405-432, 2013.

DELGADO, Richard; STEFANCIC, Jean. Critical race theory: an introduction. New York: New York University Press, 2001.

FREIRE, Ana Maria Araújo. A pedagogia da libertação em Paulo Freire. São Paulo: UNESP, 2001.

FREIRE, Paulo. Pedagogia da autonomia: saberes necessários à prática educativa. 25.ed. São Paulo: Paz e Terra, 2014.

FREIRE, Paulo. Pedagogia da indignação: cartas pedagógicas e outros escritos. São Paulo: UNESP, 2000.

FREIRE, Paulo. Pedagogia do oprimido. 17.ed. Rio de Janeiro: Paz e Terra, 1987.

hooks, bell. Ensinando a transgredir: a educação como prática da liberdade. Trad. Marcelo Brandão Cipolla. São Paulo: WMF Martins Fontes, 2013.

MACHADO, Antônio Alberto. Ensino jurídico e mudança social.2. ed. São Paulo: Expresso Popular, 2009.

MACHADO, Rita de Cássia de Fraga. Autonomia. In: STRECK, Danilo R.; REDIN, Euclides; ZITKOSKI, Jaime José (Orgs.). Dicionário Paulo Freire. 2.ed. Belo Horizonte: Autêntica, 2008.

MAGENDZO, Abraham. Educación en derechos humanos: un desafío para los docentes de hoy. Santiago: Lom Ediciones, 2006.

MOREIRA, Adilson José. Pensando como um negro: ensaio de hermenêutica jurídica. Revista de Direito Brasileira, São Paulo, v.18, n.7, p.393-421, set/dez 2017.

PADILHA, Paulo Roberto. Educação em direitos humanos sob a ótica dos ensinamentos de Paulo Freire. Revista Múltiplas Leituras, v.1, n.2, p.23-35, jul/dez 2008.

REIS, Martha dos; BRABO, Tânia Suely Antonelli Marcelino. Educação, direitos humanos e exclusão social: a (in)consistência dos conceitos. In: REIS, Martha dos; BRABO, Tânia Suely Antonelli Marcelino (Orgs.). Educação, direitos humanos e exclusão social. São Paulo: Cultura Acadêmica, 2012. 
IZIQUE, Valentina Squizato; NUNES, Guilherme de Aquino Ita; SPINIELLI, André Luiz Pereira; RUSSI, Sofia Covas. Educação e(m) Direitos Humanos: propostas de uma pedagogia crítica pensada a partir de bell hooks e Paulo Freire. Dignidade Re-Vista, v.7, n.12, jul 2021.

RODRIGUES, José Welington Cavalcante; SILVA, Alexandre Magno Tavares da. Educação em e para os direitos humanos e pedagogia crítica: direitos humanos são apenas para infratores penais? Revista da Faculdade de Direito do Sul de Minas, Pouso Alegre, v.35, n.2, p.159-171, jul/dez 2019.

RUBIO, David Sánchez. Crítica a uma cultura estática e anestesiada de direitos humanos: por uma recuperação das dimensões constituintes da luta pelos direitos. Revista Culturas Jurídicas, v.4, n.7, p.26-60, jan/abr 2017.

RUBIO, David Sánchez. Retos y propuestas para una educación para la ciudadanía a partir de una noción compleja e intercultural de derechos humanos. Revista Sequência, Florianópolis, v.1, n.59, p.361-386, dez 2009.

TIBBITTS, Felisa. Understanding what we do: emerging models for human rights education. International Review of Education, v.48, n.3, p.159-171, 2002.

VIOLA, Solon Eduardo Annes. Direitos humanos. In: STRECK, Danilo R.; REDIN, Euclides; ZITKOSKI, Jaime José (Orgs.). Dicionário Paulo Freire. 2.ed. Belo Horizonte: Autêntica, 2008.

WALSH, Catherine. Pedagogías decoloniales: prácticas insurgentes de resistir, (re)existir y (re)vivir. Equador: Abya-Yala, 2017. 